\title{
Inhibition of Rgs10 Expression Prevents Immune Cell Infiltration in Bacteria-induced Inflammatory Lesions and Osteoclast-mediated Bone Destruction
}

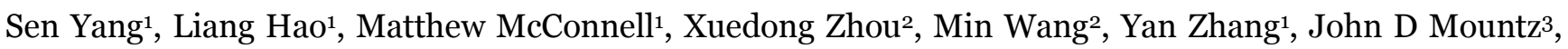 \\ Michael Reddy ${ }^{4}$, Paul D. Eleazer5, Yi-Ping Li1 ${ }^{1 *}$, Wei Chen ${ }^{1 *}$ \\ ${ }^{1}$ Department of Pathology, University of Alabama at Birmingham, Birmingham, Alabama, USA; ${ }^{2}$ The State Key Laboratory of \\ Oral Diseases, West China College of Stomatology, Sichuan University, Sichuan, P. R. China; 3Department of Medicine, \\ University of Alabama at Birmingham, Birmingham, Alabama, USA; 4 Department of Periodontology, University of Alabama \\ at Birmingham School of Dentistry, Birmingham, Alabama, USA; 5Department of Endodontics, University of Alabama at \\ Birmingham, Birmingham, Alabama, USA
}

Regulator of G-protein Signaling 10 (Rgs10) plays an important function in osteoclast differentiation. However, the role of Rgs10 in immune cells and inflammatory responses, which activate osteoclasts in inflammatory lesions, such as bacteria-induced periodontal disease lesions, remains largely unknown. In this study, we used an adeno-associated virus (AAV-) mediated RNAi (AAV-shRNA-Rgs10) knockdown approach to study Rgs10's function in immune cells and osteoclasts in bacteria-induced inflammatory lesions in a mouse model of periodontal disease. We found that AAV-shRNA-Rgs10 mediated Rgs10 knockdown impaired osteoclastogenesis and osteoclast-mediated bone resorption, in vitro and in vivo. Interestingly, local injection of AAV-shRNA-Rgs10 into the periodontal tissues in the bacteria-induced inflammatory lesion greatly decreased the number of dendritic cells, T-cells and osteoclasts, and protected the periodontal tissues from local inflammatory damage and bone destruction. Importantly, AAV-mediated Rgs10 knockdown also reduced local expression of osteoclast markers and pro-inflammatory cytokines. Our results demonstrate that AAVshRNA-Rgs10 knockdown in periodontal disease tissues can prevent bone resorption and inflammation simultaneously. Our data indicate that Rgs10 may regulate dendritic cell proliferation and maturation, as well as the subsequent stimulation of T-cell proliferation and maturation, and osteoclast differentiation and activation. Our study suggests that AAV-shRNA-Rgs10 can be useful as a therapeutic treatment of periodontal disease.

Keywords: Rgs10; immune cell; AAV-mediated RNAi knockdown; gene therapy; periodontal disease; gingival inflammation; bone resorption

Bone Research (2013) 3: 267-281. doi: 10.4248/BR201303005

\section{Introduction}

Periodontitis is a chronic inflammatory disease of the

*Correspondence: Wei Chen and Yi-Ping L

E-mail: wechen@uab.edu; ypli@uab.edu

Tel: 205-975-2606(7); Fax: 205-975-4919

Received 25 J une 2013; Accepted 28 J uly 2013 gums and supporting tissue, and one of the most common oral diseases, along with the related disease, gingivitis (1). It is initiated by a polymic robial infection, with a prominent pathogen being Porphyromonas gingivalis (2). The pathogenesis of periodontitis involves the formation of bacterial biofilms that develop on the tooth surface and within the gingival crevice, and which eventually induce a host inflammatory response in the 
local oral environment (3-4). The response results in osteoclast-mediated bone loss and the consequent loss of teeth. Furthermore, periodontitis is involved in several systemic diseases, including stroke, diabetes (5), heart disease (6) and adverse pregnancy outcomes (7). Inhibiting the function of RANKL produced by activated T-cells, can prevent alveolar bone loss, which provides strong evidence that T-cell activation mediates bone loss via recruitment and activation of osteoclasts (8). Since some of the effects of RANKL are mediated by Regulator of G-protein signaling 10 (Rgs10) (9), it is a logical target for consideration for inhibiting bone loss responsible for tooth loss (10).

Though many studies have tried to develop therapies for periodontal disease, there is still an urgent need for better therapeutic strategies. RGS proteins are a family of 21 proteins (i.e. RGS1-14 and RGS16-22), all of which contain the RGS domain and are involved in cell proliferation and differentiation (11-12). Rgs10 belongs to the subgroup D/R12 (along with RGS12 and RGS14) and is known to act specifically on activated forms of three Ga proteins (Gai3, Gaz, and Gao), which are activated by RANK/RANKL signaling. Rgs10 has been shown to regulate osteoclastogenesis by mediating calcium oscillation (13), and studies have demonstrated that Rgs10 is a key molecule that contributes to the termination of Galpha-dependent signaling during chemokine-activated alpha4beta1- and alphaLbeta2-dependent T-cell adhesion, which indicates that Rgs10 might play a key role in initiating T-cell mediated immune responses (14). Notably, RGS16 has been shown to attenuate pulmonary Th2/Th17 inflammatory responses by acting on lymphocyte migration (15). However, the role of Rgs10 in the development of periodontitis and in mediating, or inhibiting, immune cell chemotaxis, in vivo, is still unclear and in need of investigation. Rgs10 may be an ideal target for inhibiting both bone loss and inflammation involved in periodontitis.

The AAV-mediated gene silencing approach is a novel and effective tool that has been proven successful in humans in a clinic al setting, with at least 15 clinic al trials using AAV underway, some of which are already in phase 3 (16). In addition, this approach has been proven safe and well tolerated by patients with advanced Parkinson's disease, suggesting that in vivo gene therapy is safe, and that it only causes a very mild immune response (16). Furthermore, studies have recently demonstrated the impressive ability of AAV-mediated gene silencing to be effective long-tem in varying doses (17). Adeno-associated virus is capable of inserting a specific therapeutic gene with high certainty into the genome, maintaining long tem gene expression, and being non- pathogenic. Recently, it has even shown successful local knockdown, allowing for gene therapy with localized and specific manipulation of the expression of single or multiple genes in vivo (18).

The goal of this study is to analyze the underlying mechanism and direct role of Rgs10 in the pathogenesis and progression of periodontal disease, both in vivo and in vitro. This study may lead to a radical improvement in periodontal disease treatment through the novel application of adeno-associated virus (AAV) knockdown of Rgs10, which has the potential to serve as a single target for gene therapy that will simultaneously reduce inflammation and bone resorption.

\section{Materials and methods}

\section{Ethic sstatement}

All experimental protocols were approved by the $\mathrm{NIH}$ and the Institutional Animal Care and Use Committee of UAB and completed within 16 weeks after birth (19). Approval for the animal protocol related to this study (Animal Protocol Number 121209236) was renewed by the University of Alabama at Birmingham (UAB) Institutional Animal Care and Use Committee (IACUC) on December 10, 2012.

\section{Animals and experimental groups}

Seven to eight-week-old female wild-type (WT) BALB/CJ mice, purchased from the Jackson Laboratory, were used for this study. Mice were divided into 3 groups of 6 mice each: Nomal group (no bacterial infection); $P$. gingivalis W50 infection and AAV-shRNA-Rgs10 (hereafter referred to as AAV-sh-Rgs10) treatment group, $\mathrm{P}$. gingivalis W50 infection and AAV-sh-luc-YFP treatment group. The experiments were performed in triplicate on three independent occasions. The animals were maintained in the University of Alabama at Bimingham (UAB) animal facility, and were given distilled water and lab chow ad libitum.

\section{Cells and cell culture}

Pre-osteoclasts and mature osteoclasts in primary culture were generated from mouse bone marrow (MBM), as previously described (20). Briefly, MBM was obtained from tibiae and femora from six-week-old female WT

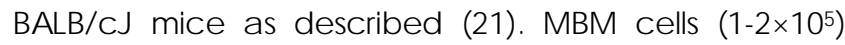
were seeded into wells of a 24-well plate and $1 \times 10^{6}$ MBM cells were seeded into wells of a 6-well plate. MBM was cultured in a-modified Eagle's medium (a-MEM; GIBCO, USA) with $10 \%$ fetal bovine serum (FBS; GIBCO, USA) containing $10 \mathrm{ng} \cdot \mathrm{mL}^{-1}$ macrophage colony-stimulating factor (M-CSF) (R\&D Systems, USA). After 24 hours, 
cells were further cultured in the presence of $10 \mathrm{ng} \cdot \mathrm{mL}^{-1}$ RANKL (R\&D Systems, USA) and $10 \mathrm{ng} \cdot \mathrm{mL}^{-1} \mathrm{M}-\mathrm{CSF}$ for additional 96 hours RANKL/M-CSF stimulation to generate mature osteoc lasts.

\section{Design and construction of shRNA}

Using the Dharmacon siDESIGN centre (http://www. dharmacon.com) as described in our recent publication (20), we generated shRNA that would target Rgs10. As a control vector, we used AAV-H1-shRNA-luc-YFP (gift from Dr. Sonoko Ogawa), which contains a luciferasespecific shRNA and a yellow fluorescent protein (YFP) cassette (22). AAV-H1 (a gift from Dr. Sonoko Ogawa) contains a human Pol III $\mathrm{H} 1$ promoter for expression of shRNA, as well as an independent enhanced green fluorescent protein (eGFP) expression cassette. We cloned the $\mathrm{H} 1$ promoter shRNA expression cassette into the AAV construct as described (23). The following shRNA oligonucleotides were annealed and cloned downstream of the $\mathrm{H} 1$ promoter of $A A V-H 1$ into $B g l l l$ and Hindlll sites to produce AAV-H1-shRNA-Rgs10 5'GATCCCCGGAGATCTACATG ACC TIC TICAAGAGAGAAGGTC ATGTAGATCTCCTITIGGAAT3' nucleotides specific for targeting Rgsl0 are underlined (9). The bold type signifies the 9-base pair hairpin spacer.

AAV RNAi viral production and punification We used the AAV pHelper-Free System (AAV HelperFree System Catalog \#240071, Stratagene, USA) for viral production, which was accomplished using a tripletransfection, helper-free method, and purified with a modified version of a published protocol (24). Briefly, HEK 293 cells were cultured in ten $150 \times 25 \mathrm{~mm}$ cell culture dishes and transfected with pAAV-shRNA, pHelper and pAAV-RC plasmids (Stratagene, USA) using a standard calcium phosphate method. Cells were collected after 60-72 hours and lysed via shaking with chloroform at $37{ }^{\circ} \mathrm{C}$ for 1 hour. Sodium chloride was then added and shaken at room temperature for 30 minutes. The stock was then spun at $12000 \mathrm{r} \cdot \mathrm{min}^{-1}$ for 15 minutes and the supematant was collected and cooled on ice for 1 hour with PEG 8000 . The solution was spun at $11000 \mathrm{r} \cdot \mathrm{min}^{-1}$ for 15 minutes, and then the pellet was treated with DNase and RNase to eliminate unincorporated DNA and RNA. After the addition of chloroform and a five minute centrifugation at $12000 \mathrm{r} \cdot \mathrm{min}^{-1}$, the purified virus was in the aqueous phase at viral particle numbers of $1 \times 10^{10}$ per $\mathrm{mL}$. The AAV particle titer was detemined by QuickTiter $^{\mathrm{TM}}$ AAV Quantitation Kit (Cell Biolabs, USA) following the manufacturer's protocol. To confim the effect of silencing, we examined the expression of Rgs10 in osteoclasts using Westem blot.
Infection with Porphyromonas gingiva lis W50

Porphyromonas gingivalis (P. gingivalis) W50 (ATC C : 53978) was cultured on sheep's blood agar plates supplemented with Hemin and Vitamin K (BAPHK) for 3 days. A single clone was harvested and transferred to Trypticase Soy Broth supplemented with Hemin and Vitamin K, and allowed to grow. On day 4, P. gingivalis W50 was harvested and resuspended at $10^{10}$ cells per $\mathrm{mL}$ in PBS containing 2\% carboxymethylc ellulose (CMC: Sigma-Aldrich, USA). The periodontal infection was conducted as previously described (25), with the following modifications. In brief, all animals received antibiotic treatment for 3 days to reduce the endogenousoral flora, followed by a 3 day antibiotic-free period, and then oral inoculation with a dental micro-brush of $0.2 \mathrm{~mL}$ of $\mathrm{P}$. gingiva lis W50, resuspended in $20 \mu \mathrm{L}$ PBS with CMC, once perday for 4 consecutive days. To monitor bacterial colonization, the oral ca vity of each mouse was sampled on day 14 after P. gingivalis infection, with a sterile cotton swab, and samples were incubated anaerobically to identify $P$. gingiva lis W50 as desc ribed (25).

AAV-shRNA-Rgs10 transduction of $P$. gingivalis W50 infected mice

We injected AAV-sh-Rgs10 in a site-specific manner as described previously (26). In brief, mice were anesthetized via peritoneal injection with $80 \mathrm{mg} \cdot \mathrm{kg}^{-1}$ ketamine and $12.5 \mathrm{mg} \cdot \mathrm{kg}^{-1}$ xylazine according to body weight. Each mouse wasthen injected with $3 \mu \mathrm{L}\left(2 \times 10^{9}\right.$ packaged viral particles in PBS) of either AAV-sh-Rgs10 or AAV-shluc-YFP viral vector using $5-\mu$ l Hamilton syringe attached to a microinfusion pump at approximately $0.3-0.5 \mathrm{~mm}$ below the gingival margin of the maxillary molars on the right and left palatal sides. AAV-sh-Rgs10 or AAV-sh-lucYFP was locally injected into the gingival tissue one day after four consec utive days of P. ging iva lis W50 ad ministration. As a negative control (nomal), mice were not infected with P. gingivalis W50. As a positive control (disease model), P. gingivalis-infected mice were treated with AAV-sh-luc-YFP viral vector.

Harvest and preparation of tissue samples

Animals were sacrificed by $\mathrm{CO}_{2}$ inhalation on day 55 after the first infection. The maxillae were obtained and hemisected. Three samples, per treatment, from the left side, were defleshed in $2.6 \%$ sodium hypochlorite for bone measurement analysis. The concentration of sodium hypochlorite was determined according to a pilot study conducted for the purpose of developing a protocol for removing the soft tissue from the bone as previously outlined (27). To perform the defleshing the samples were soaked in $2.6 \%$ sodium hypochlorite for 
30-40 minutes, rinsed in tap water 3 times, placed in $70 \%$ alcohol, stained with $1 \%$ methylene blue, and then mounted on microscope slides for bone loss measurements. The three samples from the right side were immediately fixed in $4 \%$ parafomaldehyde and prepared for histological analysis according to standard protocol with modification as follows. In brief, samples for paraffin sections were fixed in $4 \%$ formaldehyde for 24 hours, washed with PBS, decalcified in 10\% EDTA in $0.1 \mathrm{~mol}^{-\mathrm{L}^{-1}}$ TRIS solution ( $\mathrm{pH}=7.0$ ) for 10 days (with the solution replenished each day), washed with $1 x$ PBS three times and embedded in paraffin after series dehydration at the Molecular and Cellular Neuropathology Core of the University of Alabama at Bimingham. Samplesfrom the right side, in each independent experiment, were obtained for Real-Time quantitative PCR (qRT-PCR) analysis, and samples from the left side were obtained for Enzyme linked immunosorbent assays (EUSAs). Gingival tissues and/or alveolar bone were isolated under a surgic al mic rosc ope. Gingival tissues and alveolar bone from three samples were pooled for qRT-PCR, and gingival tissues from another three samples were pooled forEUSAs in each independent experiment.

\section{Bone loss measurements}

The imaging wasca mied out aspreviously described (28). Briefly, images of molar tooth roots and alveolar bone were captured using digital microscopy. The area of periodontal bone loss was determined using Adobe Photoshop ${ }^{\mathrm{TM}}$ (Adobe Systems, USA). In addition, the polygonal area enclosed by the cemento-enamel junction, the lateral margins of the exposed tooth root and the alveolar ridge, was measured using the ImageJ analysis software (Wayne Rasband, NIH, USA). Measurements were expressed in $\mathrm{mm}^{2}$.

\section{Westem blotting a nalysis}

Westem blotting was performed as previous outlined (9), and visualized using ChemiDoc ${ }^{\mathrm{TM}}$ XRS+ system (Bio-Rad, USA), and quantified by using ImageJ (Wayne Rasband, NIH, USA). A goat anti-Rgs10 antibody (Santa Cruz Biotechnology, USA) was used at a 1:1000 dilution, with rabbit anti-goat IgG-HRP (Santa Cruz Biotechnology, USA) used at a 1:5000 dilution used to visua lize the blot.

Immunofluorescence a nalysis

We performed immunofluorescence a nalysis as outlined previously (28-29). Primary antibodies included rabbitanti-CD3 (Abcam, USA) (1:200) and Amenian hamsteranti-CD11c (Biolegend, USA) (1:200). Secondary antibodies included FITC-goat-anti-rabbit antibody (Santa Cruz Biotechnology, USA) and FITC-goat-anti-Armenian hamster (Biolegend, USA). Data was documented using Axiovision (Ver. 4.8, Carl Zeiss, USA) on a Zeiss Axio mic roscope in the Developmental Neurobiology Imaging and Tissue Processing Core at the UAB Intellectual and Developmental Disabilities Research Center. Nuclei were visua lized with $1 \mu \mathrm{g} \cdot \mathrm{mL}^{-1}$ DAPI (4',6-d ia mid ino-2-phenylindole; Sigma, USA). The experiments were performed, in triplic ate, on three independent occasions.

\section{Real-time quantitative PCR (qRT-PCR)}

To determine the effect of Rgs10 knockdown on the levels of regulatory cytokines in inflammatory periodontal tissues, gingival tissues and alveolar bone were isolated and kept at $-80{ }^{\circ} \mathrm{C}$. The prepared samples were then transferred to a tube pre-filled with beads (Nextadvance Company, USA) and homogenized using a Bullet Blender ${ }^{\circledR}$ using speed 10 for 10 minutes (Nextadvance Company, USA). RNA extraction was camied out according to the standard procedure using Trizol reagent (Invitrogen, USA). The extracted RNA was reverse transcribed using the VILO ${ }^{\circledR}$ Master Mix kit (Invitrogen, USA). qRT-PCR was performed using TaqMan probes purchased from Applied Biosystems according to the manufacturer's instructions. Briefly, cDNA fragments were amplified by TaqMan ${ }^{\circledR}$ Fast Advanced Master Mix (Applied Biosystems, USA). Fluorescence from each TaqMan probe was detected using the StepOne ${ }^{\mathrm{TM}}$ real-time PCR system (Applied Biosystems, USA). The mRNA expression level of the housekeeping gene hypoxanthineguanine phosphoribosyl tranferase (Hprt) was used as an endogenous control and enabled the calculation of specific mRNA expression levels as a ratio of Hprt (deltaCT). qRT-PCR was performed under standard conditions and repeated at least three times.

\section{Enzyme-linked immunosorbent assay (EUSA)}

To determine the effect of Rgs10 knockdown on the levels of regulatory cytokines in inflammatory gingival tissues, we used ELISA as previously described (28-29). Briefly, assays for cytokines in the tissue extracts used commercially a vailable EUSA kits that are obtained from the following sources: IL-1 a (Biolegend, USA), IL-6, IL-17A and TNF-a (eBioscience, USA). All assays were conducted in accordance with the manufacturer's instructions with results expressed as pg cytokine per $\mathrm{mL}$.

Statistic al a nalysis and data quantific ation a nalysis Experimental data were reported as mean \pm standard deviation. All experiments were performed in triplicate on three independent occasions. Bone loss measurement, histological, qRT-PCR and EUSA data were analyzed with the ANOVA. $P$ values $\varangle .05$ were considered 
significant. Measurements of immunofluorescence were analyzed using the Mann-Whitney $U$ test, $U>1.96$ was denoted as $P$ values $\varangle 0.05$. Data quantific ation analyses were performed using NIH ImageJ asdescribed (30).

\section{Results}

AAV-shRNA-Rgs10 targeted Rgs10 mRNA and efficiently knocked down the expression of Rgs10

In order to silence the osteoimmune gene Rgs10, we generated the Rgs10 targeting shRNA vector, which was then named AAV-shRNA-Rgsl0 and abbreviated as AAV-sh-Rgs10. In order to determine the ability of our newly generated AAV-sh-Rgs10 and the AAV-sh-luc-YFP (control) to transduce T-cells, we examined the expression of eGFP orYFP in T-cells. Mouse bone marrow (MBM), isolated from wild-type (WT) BALB/cJ mice, wascultured with M-CSF and RANKL to generate osteoclasts, which were then transduced with AAV-sh-Rgs10 or AAV-sh-luc-
YFP. Cellular fluorescence indicates that effic ient transduction of pre-osteoclasts and osteoclasts with AAV-shRgs10 or AAV-sh-luc-YFP was achieved (Figure 1A). To confirm the effect of AAV-sh-Rgs10 on gene silencing, we performed Westem blot quantification and determined that osteoclasts transduced with AAV-sh-Rgs10 have a significant reduction in Rgs10 expression compared to osteoclasts transduced with AAV-sh-luc-YFP $(P \varangle 0.01)$ (Figure 1B and $1 C$ ). We then performed tartrateresistant acid phosphatase (TRAP) staining; the results showed that the number of TRAP-positive osteoclasts decreased signific antly in the AAV-sh-Rgslo group (Figure 1D). Wheat germ agglutinin (WGA) staining and scanning electron mic roscopy (SEM) revealed a significant decrease in bone resorption in the AAV-sh-Rgsl0 group (Figure 1D and 1E). Overall, our results indicated that AAV-sh-Rgs10 effic iently reduces Rgs10 protein expression and the formation and function of osteoclasts.
A

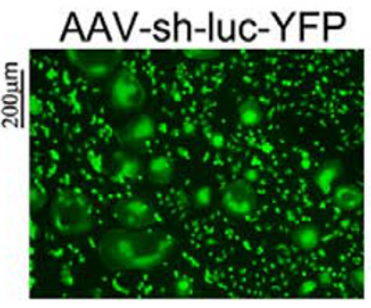

D $200 \mathrm{~mm}$ TRAP
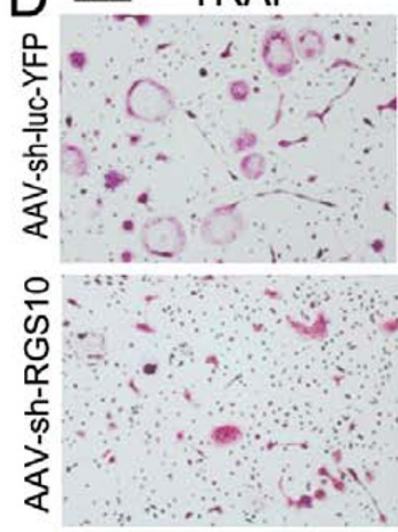
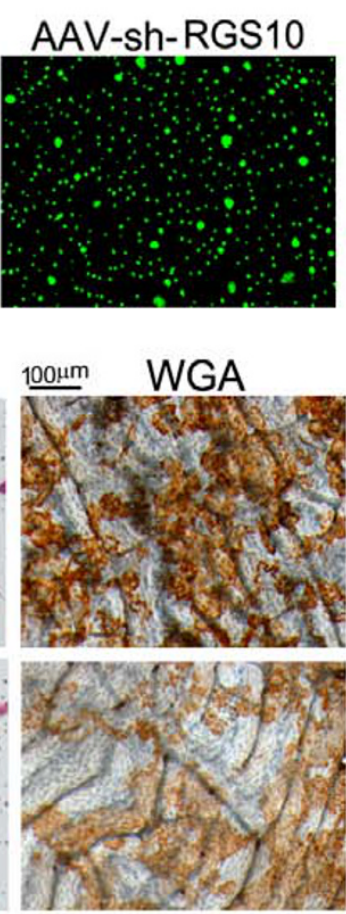

B

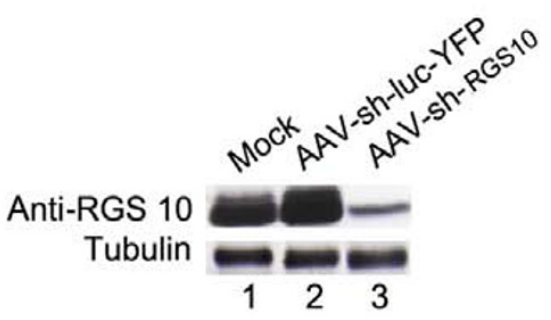

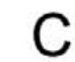
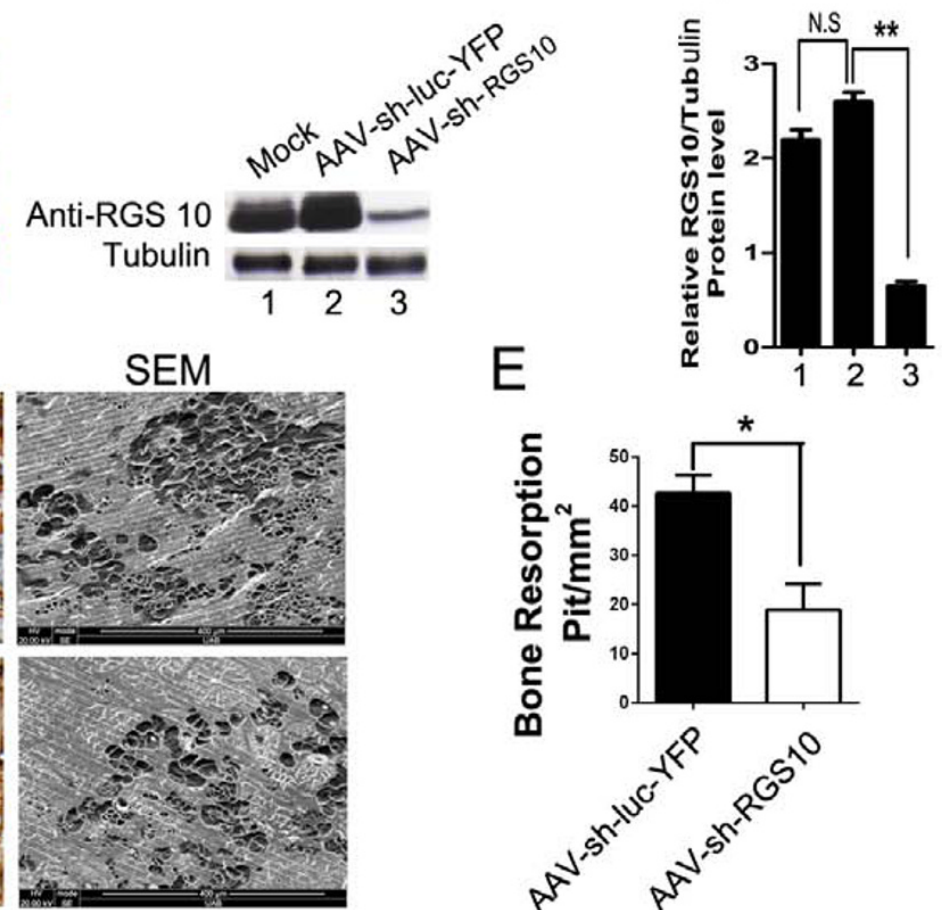

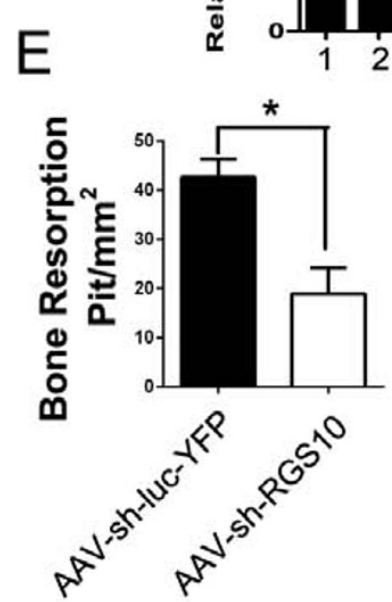

Figure 1 AAV-sh-Rgs10 targets Rgs10 mRNA and efficiently knocks down the expression of Rgs10. (A-E) MBM was stimulated with M-CSF/RANKL for 3 days to allow for differentiation of osteoclasts, which were then transduced with AAV-sh-luc- YFP (control vector) or AAV-sh-Rgs10 or left untreated (mock). (A) Fluorescence indicates effective transduction of pre-osteoclasts and osteoclasts. (B, C) Western blot and quantification of Rgs10 protein level demonstrate that AAV-sh-Rgs10 treated osteoclasts have significantly reduced expression of Rgs10 (P<0.01). (D) TRAP stain reveals that the number of osteoclast is decreased in the AAV-sh-Rgs10 treatment group. Resorption lacunae were visualized by wheat germ agglutinin (WGA) and scanning electron microscopy (SEM), which demonstrates that Rgs10 knockdown inhibits osteoclast-mediated bone resorption. (E) Quantification of resorption pits on bone slices visualized by SEM showed a significant decrease in the degree of bone resorption in the AAV-sh-Rgs10 treatment group $(P<0.01)$. N.S: no significant; ${ }^{*} P<0.05 ;{ }^{* *} P<0.01$.

www.boneresearch.org | Bone Research 
AAV-mediated Rgs10 knockdown protected mice from bone loss in P. gingivalis W50-stimulated periodontitis To determine if our AAV vectors could effectively transduce periodontal tissues in vivo, we examined expression of YFP following injection of AAV-sh-luc-YFP into gingival tissue on the right side of the maxilla in twelve locations as indicated (Figure 2A). Local injection of AAV-sh-luc-YFP in vivo transduced periodontal tissues (Figure 2A). These data demonstrated that our AAVmediated gene therapy is able to effectively transduce periodontal tissue, and that injection of AAV into gingival tissue results in localized and sustained synthesis of gene products. To further test if Rgs10 knockdown by local injection protects mice from $\mathrm{P}$. gingivalis W50-stimulated bone loss, we analyzed the degree of alveolar bone loss in uninfected BALB/CJ mice (nomal) compared to $P$. gingiva lis W50-infected mice treated with AAV-sh-Rgs10 or with AAV-sh-luc-YFP (Figure 2B). AAV-sh-Rgs10 or AAVsh-luc-YFP was locally injected into the gingival tissue one day after four consec utive days of $P$. ging iva lis W50 administration. There was no significant difference in bone loss between the uninfected nomal group and the infected group treated with AAV-sh-Rgs10 ( $P>0.05)$ (Figure 2B and 2C). However, the AAV-sh-luc-YFP treatment group had signific antly more bone loss, compared to the AAV-sh-Rgs10 group ( $\mathrm{Q} \varangle 0.01$ ) or the nomal group $(\mathrm{P} \varangle 0.01)$ (Figure 2C). Indeed, AAV-mediated Rgs10 knockdown largely protected mice from $P$. gingivalis W50 infection-stimulated bone resorption. These results indicate that Rgs10 knockdown protects against $P$. gingivalis W50-stimulated bone loss in the mouse model of periodontal disease.

AAV-mediated Rgs10 knockdown decreased bone resorption and the number of T-cells and dendritic cells (DCs) in the periodontal lesion

In order to determine if the periodontal membrane area between the tooth root and the alveolar bone is normalized by AAV-sh-Rgs10 treatment, we examined hematoxylin \& eosin-stained sections from uninfected (nomal) mice and P. gingivalis W50-infected mice treated with AAV-sh-Rgs10 or AAV-sh-luc-YFP. We found that the periodontal membrane area between the tooth root surface and the alveolar bone increased in the control AAV-sh-luc-YFP treatment group, compared to the normal and AAV-sh-Rgs10 treatment groups (Figure 3A) (Red Dot Area), indicating that AAV-sh-Rgsl0 prevents periodontal ligament damage induced inflammation and alveolar bone resorption, as comelates of loss of bone attachment (Black Arrows) (Figure 3B and

A
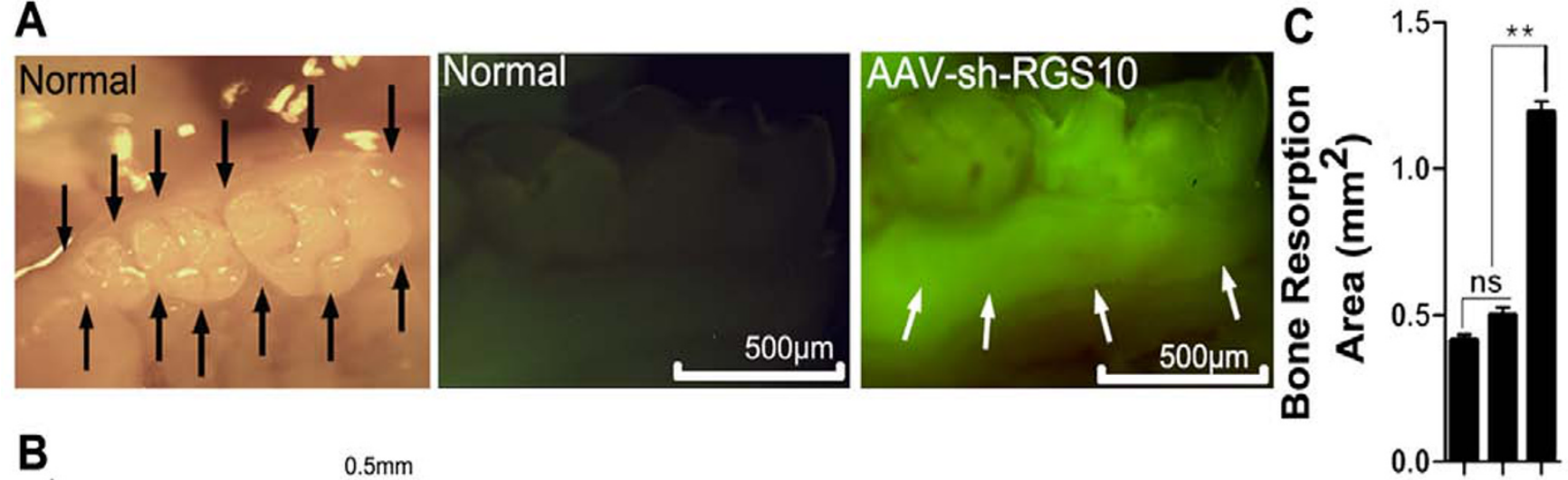

B $0.5 \mathrm{~mm}$
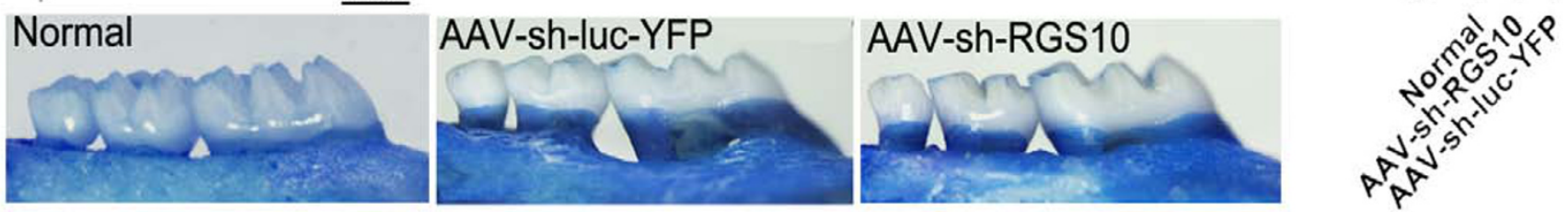

Figure 2 AAV effectively transduced periodontal tissue and Rgs10 knockdown efficiently protected mice from bone loss in W50-stimulated periodontitis. (A) Mouse maxillary molars showing AAV injection sites (black arrows). Fluorescence microscope image reveals eGFP expression after local injection with AAV-sh-Rgs10 compared with normal mouse tissues that did not receive AAV treatment. (B) Representative figures of periodontal bone resorption and root exposure from different groups. (C) There was no significant difference in bone loss between the normal group and the AAV-sh-Rgs10 treatment group $(P>0.05)$. In addition, the AAV-sh-Rgs10 treatment group had significantly less bone loss compared with the AAV-sh-luc- YFP treatment group $(P<0.01)(N=9, n=3$ per group, repeated 3 times $)$. N.S: no significant; ${ }^{* *} P<0.01$. 


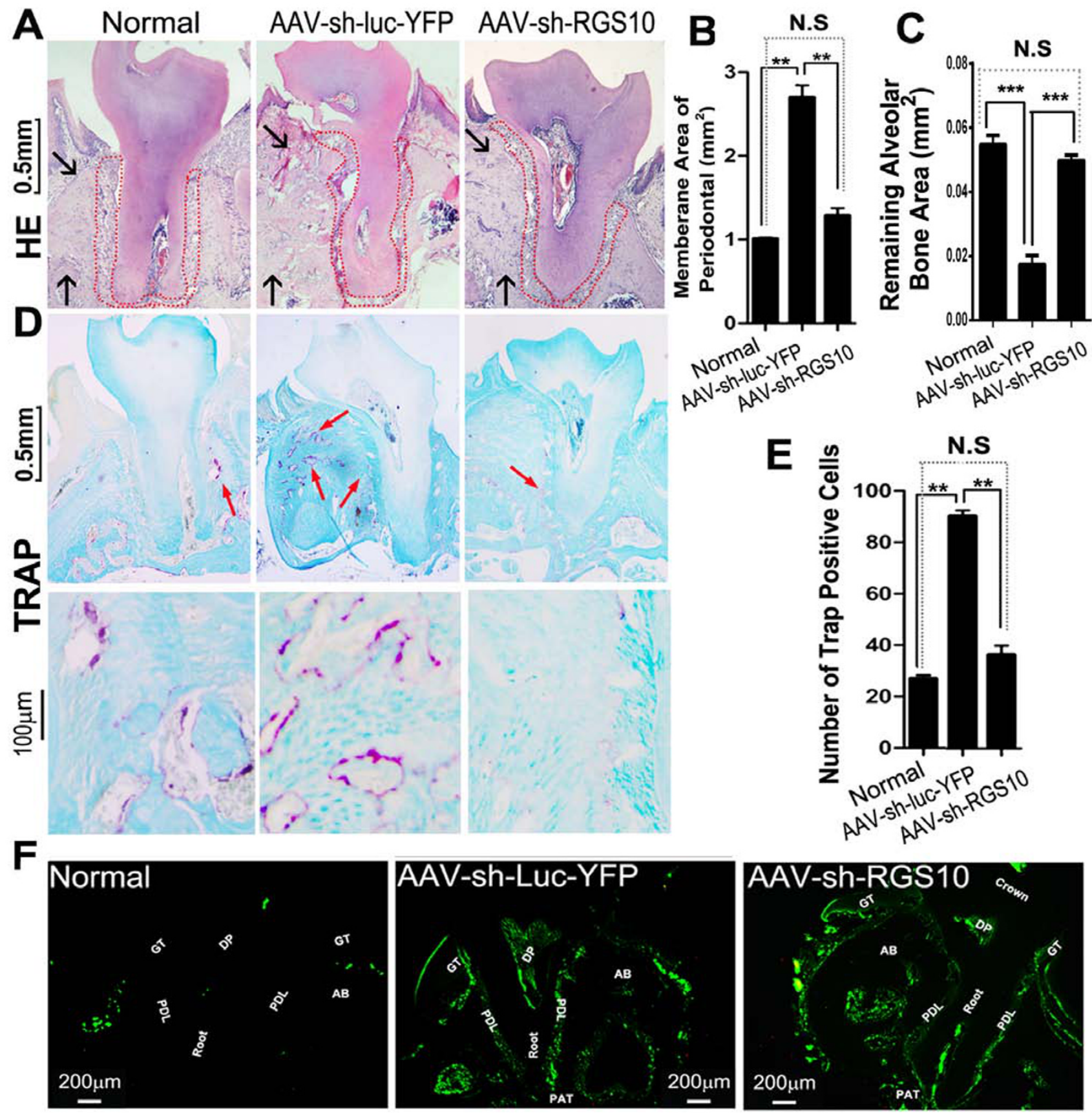

Figure $3 \mathrm{AAV}$-mediated Rgs10 knockdown decreased bone resorption and the number of TRAP-positive osteoclasts in the periodontal area. (A) Representative figures of H\&E staining from uninfected mice (Normal), W50-infected mice treated with AAV-sh-Rgs10 or AAV-sh-luc-YFP. Black arrows indicate significant change of alveolar bone in different groups, which demonstrate that the alveolar bone resorption was severe in AAV-sh-luc-YFP treatment group. And the periodontal ligament area in AAV-sh-luc-YFP treated disease group showed irregular shape compared to the normal and AAV-sh-Rgs10 treated group (red dot area). (B, C) The area of periodontal ligament increased in the AAV-sh-luc- $Y F P$ treatment group, compared to the normal and AAV-sh-Rgs10 treatment groups $(P<0.01)$ and remaining alveolar bone area was also decreased significantly in AAV-sh-luc- YFP treated disease group $(P<0.001)(N=9, n=3$ per group, repeated 3 times). (D) Representative figures of TRAP staining (counter stained with fast green) from uninfected mice (Normal), W50-infected mice treated with AAV-sh-Rgs10 or AAV-sh-luc-YFP (Red Arrows). (E) Compared with normal control group, the number of TRAP positive osteoclasts from AAV-sh-luc-YFP groups increased significantly. The AAV-sh-Rgs10 treatment group has obviously therapeutic effect, and the number of osteoclasts were close to normal control group $(P<0.01)$. (F) Fluorescence microscope image of sections reveal YFP expression after local injection with AAV-sh-luc-YFP and eGFP expression of AAV-sh-Rgs10 compared with normal mouse tissues that did not receive AAV treatment (GT: Gingival Tissue, AB: Alveolar Bone, DP: Dental Pulp, PDL: Periodontal Ligament, PAT: Periapical tissue) $\left(N=9, n=3\right.$ per group, repeated 3 times). N.S: no significant; ${ }^{* *} P<0.01 ; * * * P<0.001$. 
$3 C)$. In order to verify that AAV-sh-Rgs10 treatment reduces the number of osteoclasts in vivo, tooth root sections from normal, $P$. gingivalis W50-infected mice treated with AAV-sh-Rgs10 or AAV-sh-luc-YFP were TRAP stained (Figure 3D) (Red Arrows). We found that AAV-shRgs10 treatment notably reduced the number of osteoclasts in vivo (Figure 3E). Following local injection with AAV-sh-Rgs10 and AAV-sh-luv-YFP, YFP and eG FP expression was observed in gingival tissue, periodontal ligament, dental pulp tissue, indicating that AAV effectively diffuses throughout periodontal tissues (Figure 3F). This result, again, confimed the AAV infection of periodontal tissues. To determine the effect of AAV-sh-Rgs10 on Tcells in vivo, alveolar sections were subjected to immunofluorescence staining using CD3 antibody to detect Tcells (Figure 4). The number of $\mathrm{CD}^{+} \mathrm{T}$-cells in the periodontal ligament was signific antly reduced in the AAVsh-Rgs10 treatment group, compared to that of the AAV-sh-luc-YFP treatment group (white arrows) (Figure $4 A$ and $4 B$ ). To investigate the effect of AAV-sh-Rgslo on

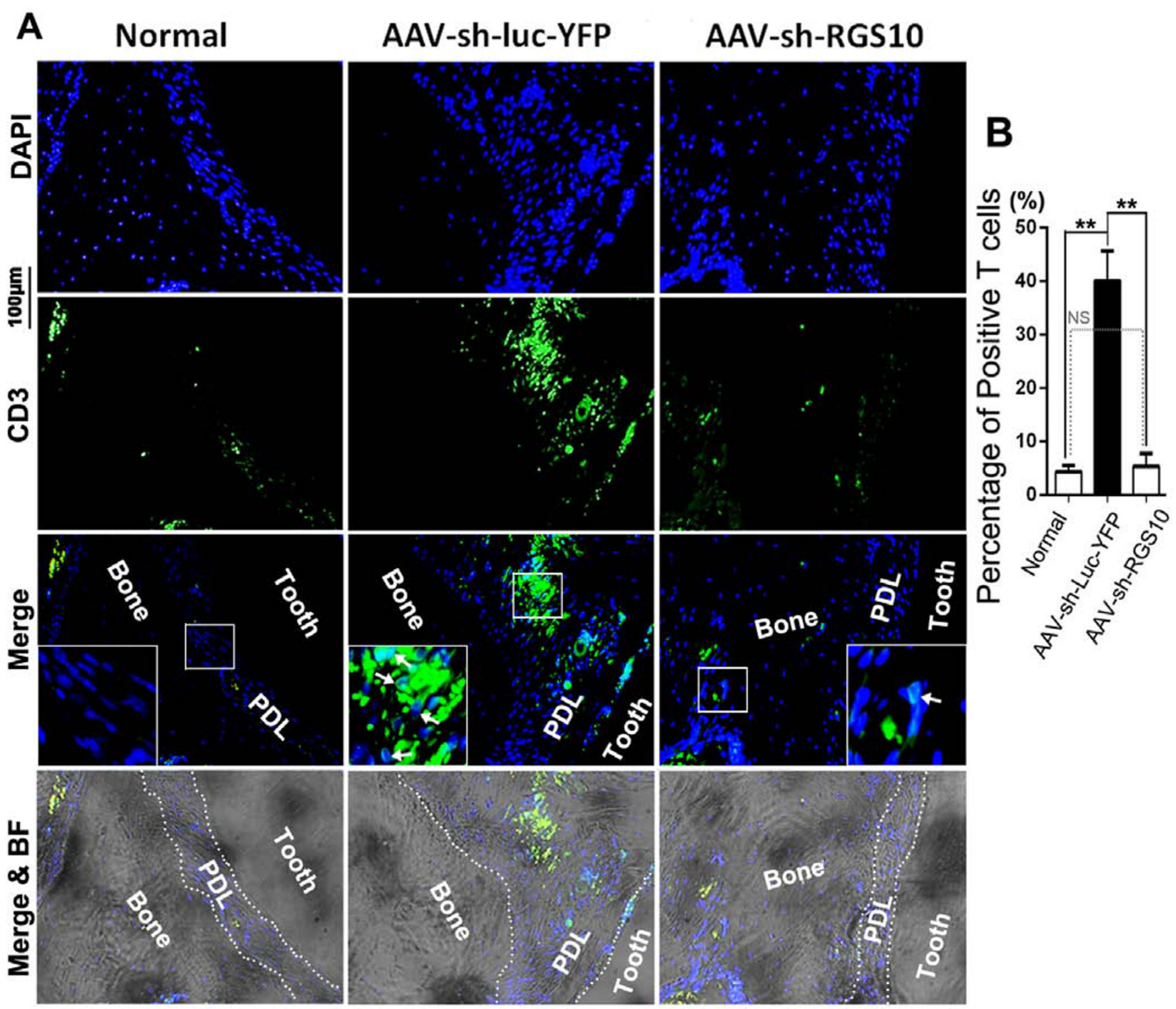

Figure $4 \mathrm{AAV}$-mediated Rgs10 knockdown decreased the number of T-cells in periodontal lesions. (A) Representative figures from immunofluorescence staining of alveolar sections indicated that uninfected mice (Normal) and W50-infected mice treated with AAV-sh-Rgs10 had less CD3 positive (green) T-cells (white arrows), compared to W50-infected mice treated with AAV-sh-luc-YFP. Cell nuclei were labeled using DAPI stain (blue) (B) Quantification of CD3 positive T-cells. ( $N=9, n=3$ per group, repeated 3 times). BF: Bright Field, PDL: periodontal ligament. N.S: no significant; ${ }^{*} P<0.05 ;{ }^{* *} P<0.01 ;{ }^{* * *} P<0.001$. 
dendritic cells (DCs) in vivo, alveolar sections were subjected to immunofluorescence staining using CD11c antibody to detect dendritic cells (DCs) (white arrows) (Figure 5A and 5B). Our results showed that the number of $C D 11 c^{+} D C s$ in the periodontal ligament was significantly reduced in the AAV-sh-Rgs10 treatment group, compared to that of the AAV-sh-luc-YFP treatment group (Figure 5B). These data demonstrate in vivo, that AAV-sh-Rgs10 powerfully protects against $P$. gingivalis W50-stimulated periodontal ligament widening, bone resomtion and inflammation.
AAV-sh-Rgs10 retumed the expression of osteoclast marker genes and infla mmatory cytokines in periodontal tissues to nomal expression levels

To investigate the effect of AAV-sh-Rgs10 on the interplay between bone resorption and inflammation, qRTPCR was used to quantify mRNA expression in periodontal tissues (Figure 6A). Compared to nomal uninfected mice, we found that expression of genes important for osteoclast differentiation (i.e. RANKL), formation (i.e. NFATC 1) and osteoclast-specific functional genes [i.e. Cathepsin $\mathrm{K}(\mathrm{Ctsk})$ ] increased in P. gingivalis W50-infected

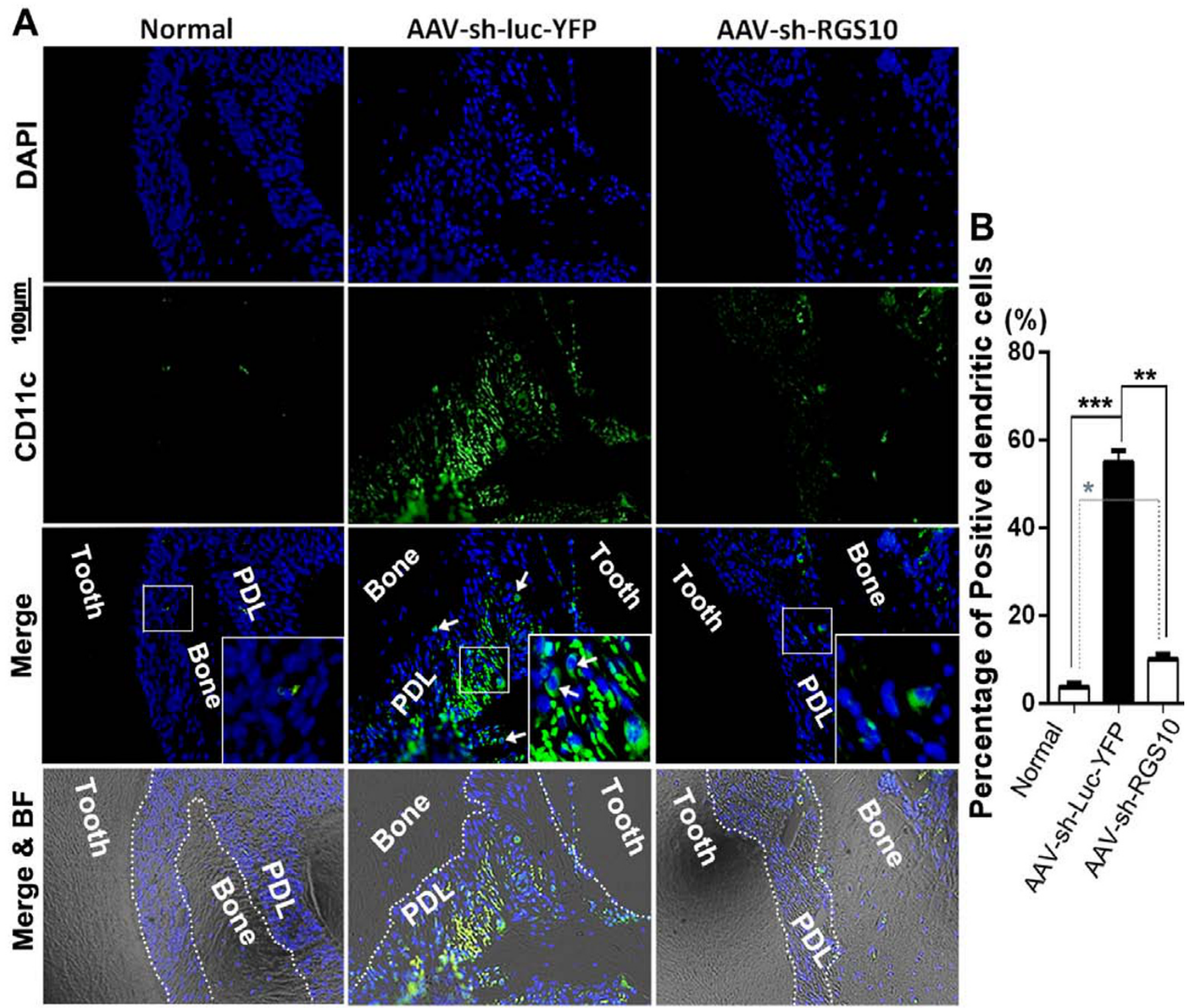

Figure 5 AAV-mediated Rgs10 knockdown decreased the number of DCs cells in periodontal lesions. (A) Representative figures from immunofluorescence staining of alveolar sections indicated that uninfected mice (Normal) and W50-infected mice treated with AAV-sh-Rgs10 had less CD11C (green) positive dendritic cells (white arrows), compared to W50-infected mice treated with AAV-sh-luc-YFP. Cell nuclei were labeled using DAPI staining (blue). (B) Quantification of CD11c positive dendritic cells ( $N=9, n=3$ per group, repeated 3 times). BF: Bright Field, PDL: periodontal ligament. ${ }^{*} P<0.05 ;{ }^{* *} P<0.01 ;{ }^{* * *} P<0.001$. 

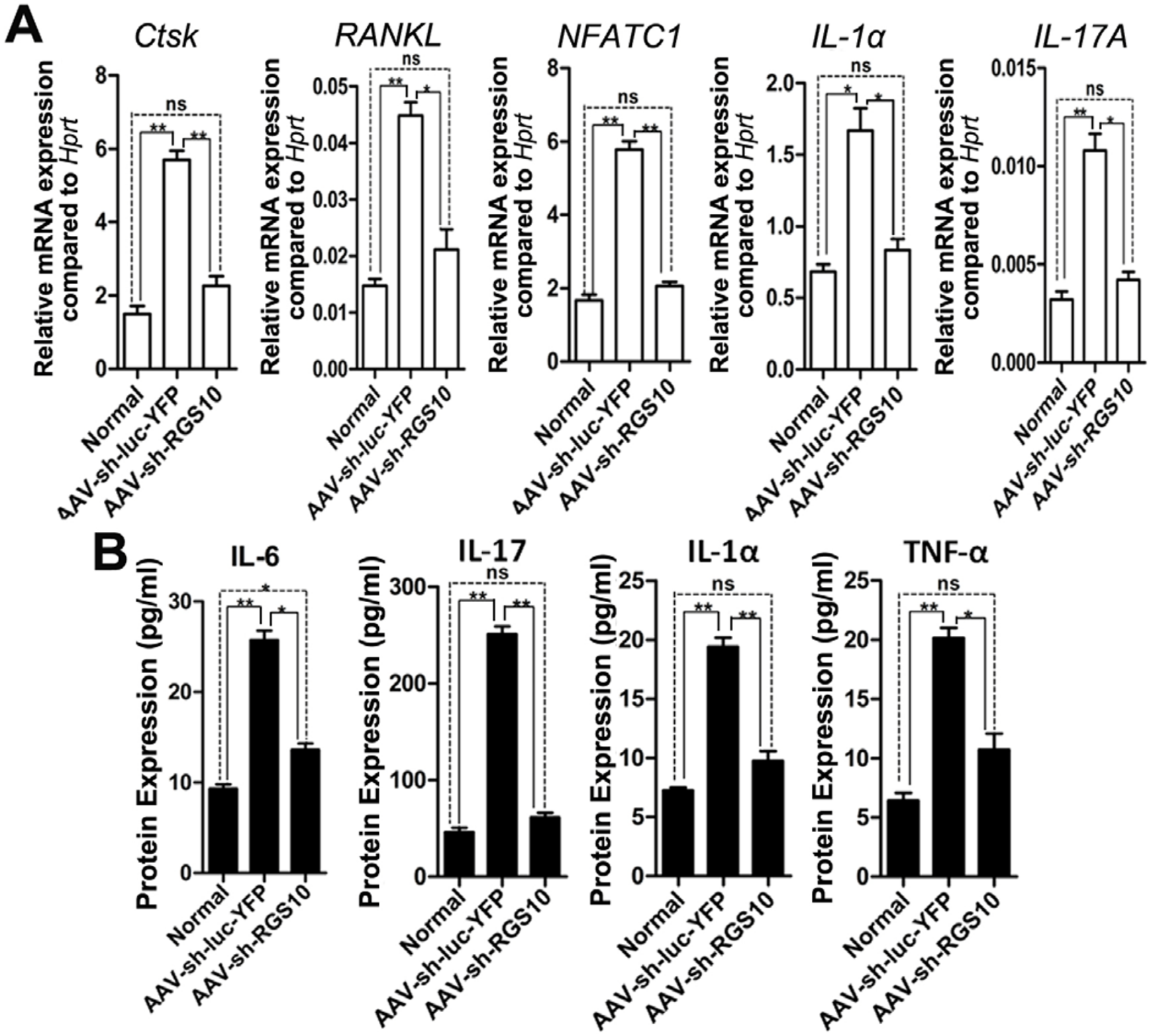

Figure $6 \mathrm{AAV}-\mathrm{sh}-\mathrm{Rgs} 10$ reduced the expression of osteoclast marker genes and cytokines in periodontal lesions. (A) qPCR of osteoclast marker genes (i.e., Cathepsin K), genes important for osteoclast differentiation (i.e., RANKL and NFATC1) and cytokines (i.e., IL-1a, and IL-17A) in the periodontal lesion from uninfected mice (Normal) or infected mice treated with AAV-sh-Luc-YFP or with AAV-sh-Rgs10. Hprt was used as an endogenous control. AAV-sh-Rgs10 reduced the expression of inflammatory cytokines in the periodontal tissues (pooled 3 samples each time in each group on three independent experiments). (B) ELISA experiment for inflammatory cytokine expression from osteoclast or T-cells in the periodontal tissues of uninfected mice (Normal) or W50-infected mice treated with AAV-sh-luc-YFP or with AAV-sh-Rgs10. The data of ELISA indicates that uninfected mice (Normal) and W50-infected mice treated with AAV-sh-Rgs10 have less inflammatory cytokines expression of IL-6, IL-1a, IL-17 and TNF-a, compared to W50-infected mice treated with AAV-sh-luc-YFP (pooled 3 samples each time in each group on three independent experiments). N.S: no significant; ${ }^{*}<<0.05 ;{ }^{* *} P<0.01 ;{ }^{* * *} P<0.001$.

mice treated with AAV-sh-luc-YFP (Figure 6A). AAV-shRgs10 treatment was able to reduce the expression of RANKL, NFATC 1, and Ctsk in P. gingivalis W50-infected mice (Figure 6A). Additionally, AAV-sh-Rgs10 treatment of $P$. gingivalis W50-infected mice resulted in decreased expression of T-cell-derived infla mmatory cytokine IL-17A and IL-la (Figure 6A). These results were confimed at the protein level by Enzyme-Linked Immunosorbent 
Assay (EUSA) of IL-1a and IL-17A in inflammatory gingival tissue (Figure 6B). And EUSA analysis also determined the effect of Rgs10 knockdown on the important mediators of inflammatory and immune response cytokines IL-6 and TNF-a, which showed decreased expression of these two pro-inflammatory cytokines (Figure 6B). These results indicate that Rgs10 knockdown reduces mRNA and protein expression of many genes important for osteoclastic bone resorption and inflammation in periodontal tissues.

\section{Discussion}

RGS proteins are reported to be involved in cell proliferation and differentiation (13). Rgs10 has been shown to have an essential role in regulating components of the RANKL signaling pathway in osteoclast differentiation, such as calcium oscillation $(9,13)$. Rgs10-1- mice have been shown to possess severe osteoclast-poor osteopetrosis because of impaired osteoclast differentiation (13). Although the role of Rgs10 in osteoclasts has been studied previously, the relationship between Rgs10 and the immune response during the development of periodontitis has not been explored. Garcia-Bemal et al. demonstrated in their studies, that Rgs10 have a critical role in T-cell adhesion (14). Furthemore, Rgs2, 3, 4, 14 and 16 have also been reported to be expressed in T-cells, which indicate that the RGS family may have functions in T-cell response (31-34).

Periodontal disease is a widespread infectious disease that prominently includes the pathogen Porphyromonas gingivalis, which has been associated with disease progression (35). In periodontitis, the relationship between host immune and inflammatory responses plays a critical role (36), by damaging soft tissue, as well as activating osteoc last-mediated alveolar bone resomtion $(10,35)$. In the current study, we demonstrated that gene knockdown with an AAV vec tor that targets the expression of Rgsi0, a regulator of G-protein signaling (RGS) family member expressed predominantly in osteoclasts, simultaneously inhibited inflammation and bone resorption to dramatically reduce periodontal disease progression. The AAV-sh-Rgs10 vector impaired osteoclastic bone resorption in vitro, through inhibition of osteoclast differentiation. Furthemore, AAV-sh-Rgs10 reduced proinflammatory cytokine expression, lowered the number of osteoclasts in the periodontal lesion, and protected mice from P. gingivalis-stimulated periodontal bone loss in vivo. This study, thus demonstrated that local application of AAV-sh-Rgs10 gene therapy efficiently protects against periodontal tissue damage, and may be a powerful new treatment stra tegy for this disease.
Targeting Rgs10 allows for increased efficiency in the treatment of inflammation and bone loss associated with periodontal disease

Our results showed that knocking down Rgs10 inhibits the function and number of osteoclasts both in vitro and in vivo (Figure 1, 2 and 3). We found that AAV-sh-Rgs10 directly impaired osteoclastic bone resorption by approximately $50 \%$, compared to AAV-sh-luc-YFP treated osteoclasts in vitro (Figure 1E). However, in vivo bone resorption was impaired by almost $70 \%$ when compared to the AAV-sh-luc-YFP treated disease group when the bone resorption in the nomal group wasconsidered the background (Figure $2 \mathrm{C}$ ). This indic ates that AAV-sh-Rgs10 treatment not only decreased the original osteoclast number, but that it also decreased the number of osteoclasts activated by inflammation. Similarly, we found that AAV-sh-Rgs10 treatment in vivo decreased the osteoclast number in the lesion area by $60 \%$ when the osteoclast number in the nomal group was considered the background (Figure 3E). Overall, these data indicated that AAV-sh-Rgs10 treatment not only reduced the number of osteoclasts, but that it also inhibited the inflammation, which activates osteoclasts, providing a possible explanation for the increased inhibition of osteoclasts in vivo (Figure $2 \mathrm{C}$ and $3 \mathrm{E}$ ), compared to that in vitro (Figure $1 E$ ). The gene therapy employed in this study also reduced the number of T-cells and DCs in the periodontal tissues of P. gingivalis-infected mice (Figure 4 and 5). AAV-sh-Rgs10 also decreased the expression of osteoclast-specific genes Ctsk, RANKL and NFATC 1, reflecting the lower number of osteoc lasts in tissues (Figure 6A). Our EUSAs and qRT-PCR analyses a lso demonstrated a decrease in inflammation in the AAV-sh-Rgs10 treatment group (Figure $6 \mathrm{~A}$ and $6 \mathrm{~B}$ ). The reduction in inflammation may be partially due to the down regulation of IL-6 protein expression (a pro-infla mmatory cytokine associated with periodontal disease). Notably, IL-6, which is secreted by osteoblasts in response to bone resorbing agents (e.g.IL-la and TNF-a) (37), promotes both inflammation and bone resomtion (38). Thus, AAV-sh-Rgs10 inhibits both processes not only through reduced expression of Rgs10, but also, indirectly, through reduced inflammatory cytokine expression. Consistent with the reduced number of T-cells in the periodontal area of $P$. gingivalis-infected mice after AAV-sh-Rgs10 treatment (Figure 4), AAV-sh-Rgs10 treatment also resulted in decreased expression of T-cell-derived infla mmatory cytokine IL-17A (Figure 6A). Our study shows that IL-17A mRNA expression is very low, while the IL-17A protein level is also decreased (Figure 6A and 6B). Our results indic ate that knockdown of Rgs10 interferes with positive feedback circuits between bone resorptive and inflam- 
matory processes related to the progression of periodontal disease.

Local delivery of AAV-sh-Rgs10 gene therapy is a promising therapeutic tool for periodontal disease and related systemic diseases

Adeno-associated virus is capable of inserting a specific therapeutic gene with high certainty into the genome, maintaining long term gene expression, and being nonpathogenic. Recently, it has even shown successful local knockdown, allowing for gene therapy with localized and specific manipulation of the expression of single or multiple genes in vivo (39). It has been reported that AAV gene transfer of mitogen-activated protein
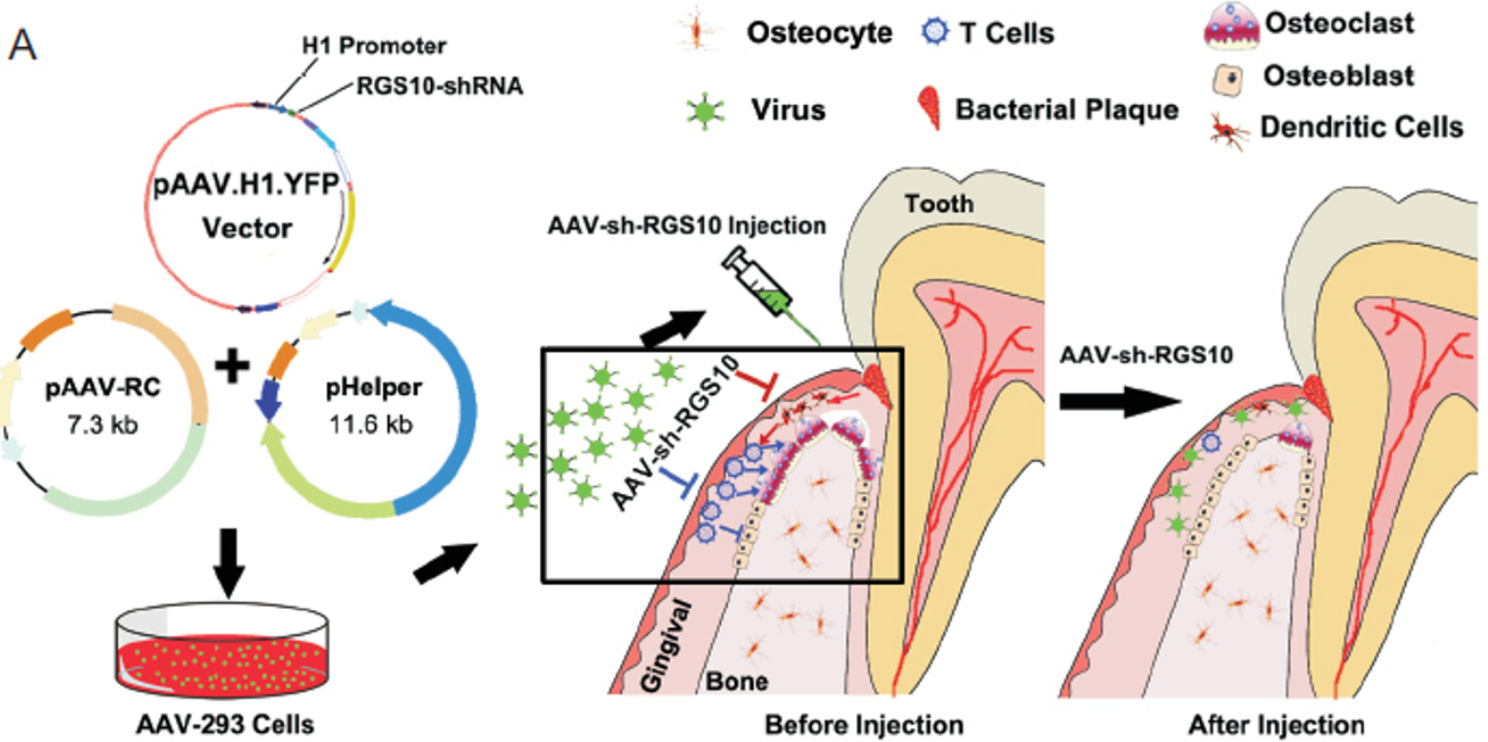

B Periodontal lesion area

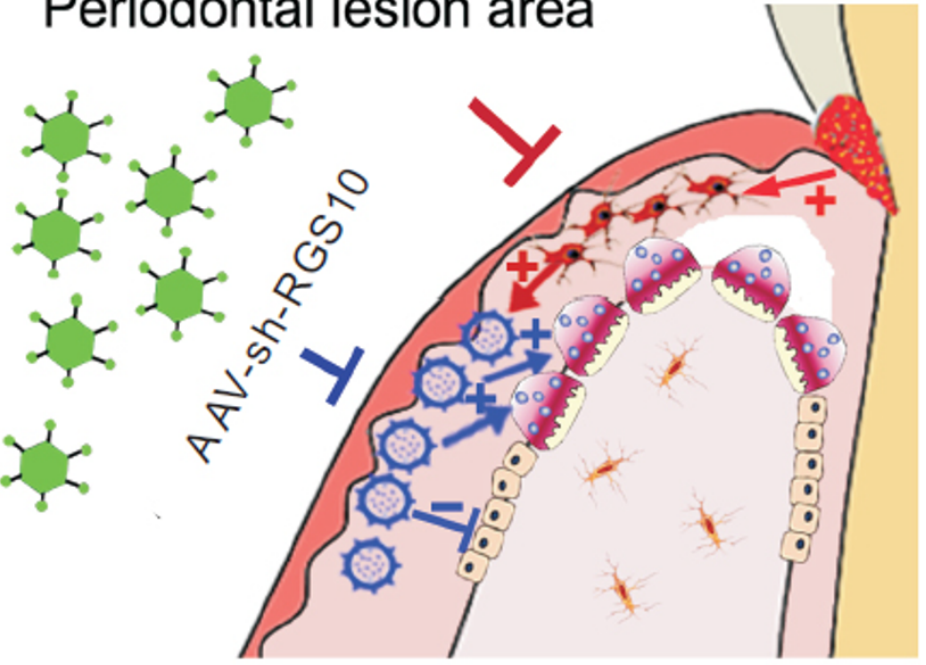

\section{AAV-sh-RGS10 inhibits immune response and bone destruction working model}

Figure 7 Diagram model for the AAV-shRNA-Rgs10 inhibits immune response in periodontal lesion. (A) The whole experiment was starting from the design of shRNA sequences, annealing shRNA stands together, linearizing pAAV.H1 vector, inserting shRNA fragment into pAAV.H1 vector, verifying clones have inserted, and finally transfecting into AAV particles to create virus. Then the virus was injected into the periodontal lesion, in which the AAV-sh-Rgs10 inhibited the immune DCs and the subsequent decrease of T-cells. And the decreased pro-inflammatory cytokines resulted in less osteoclast differentiation and activation. (B) The following immune response mediated by immune cells (i.e. DCs and T-cells) and bone resorption or formation mediated by osteoclasts and osteoblasts respectively in periodontal lesion. After contact with bacterial (red arrow), the antigen presenting cells (APCs) (i.e. DCs) presented the bacterial pathogen (dark red arrow) to T-cells and activated T-cells. Then T-cells can activate the osteoclasts and inhibit osteoblasts (blue arrow) while AAV-sh-Rgs10 can inhibit this process, which will prevent further bone loss by overactivated osteoclasts. 
kinase phosphatase-1 (MKP-1), which dephosphorylates MAPKs and inhibits immune responses, inhibits periodontal bone loss in a rat model of periodontal disease (40). AAV2 also achieved the highest transduction rates for human primary periodontal ligament cells, as well as periodontal tissues (41). Transduction of gingival tissues with $A A V / 2 / 1-T N F$ Receptor: $F c$ reduced $P$. gingivalis induced periodontal bone loss by approximately $50 \%$ in a mouse model, with concomitant reductions in proinflammatory cytokines and osteoc lasts (42). In the aforementioned study, the AAV-TNFR:Fc vector was delivered at multiple gingival sites three times per week for 8 weeks (42), compared to the single time point injections of AAV-sh-Rgs10 in the present study. The greater efficiency of Rgs10 inhibition may reflect the critical importance and synergistic function of Rgs10 in periodontal disease pathogenesis, which is critical for osteoclastic bone resorption and for T-cell-mediated inflammatory processes that induce tissue destruction, as well as osteoclast formation. Another factor may be that the vector persisted for at least 35 days after local injection of AAV into the periodontal tissue, as shown in our previous study (28), indic ating sustained synthesis of therapeutic inhibitory RNA in the gingival sites. Local delivery of gene therapy is favored over systemic administration, since local delivery restricts the synthesis of therapeutic gene products to selected sites, which minimizes exposure of non-target tissues, and reduces side effects and treatment costs (43). AAV-sh-Rgs10 inhibits periodontal bone resomtion and inflammation in a mouse model of periodontal disease, and may be useful for other diseases involving bone resorption and the immune system (Figure 7).

Recent studies have shown that periodontal disease not only leads to the loss of teeth, but that it is also associated in epidemiologic studies with atherosclerosis, coronary artery disease, premature birth, stroke and meumatoid arthritis, presumably by contributing to overall levels of systemic inflammation $(41,44-46)$. Oral microorganisms have also been linked to infections of the endocardium, meninges, mediastinum, vertebrae, hepatobiliary system and prosthetic joints $(2,47-48)$. And low birth weight has also been associated with periodontal disease due to inflammatory changes in the mother (1). Given that periodontitis is widespread and the mounting scientific evidence of the linkages between chronic oral infections and other health conditions, there is an urgent need for more effective treatments for this disease. Although AAV vector-mediated human gene therapy is still controversial due to potential side effects, this approach is in clinic al trials for a number of human diseases and is considered one of the safest gene therapy approaches (49). The use of AAV vectormediated gene therapy in the treatment of periodontal disease should continue to be evaluated.

In summary, we investigated the role of Rgs10 in immune cells, which activate osteoclasts in inflammatory lesions, and the therapeutic effect of AAV-sh-Rgs10 in periodontitis. AAV-shRNA-Rgs10 knockdown in periodontal disease tissues can prevent bone resorption and inflammation simultaneously. Rgs10 may regulate dendritic cell proliferation and maturation, as well as the subsequent stimulation of T-cell proliferation and maturation, and osteoclast differentiation and activation. AAV-shRNA-Rgs10 may be useful as a therapeutic for periodontal disease.

\section{Acknowledgements}

We thank Ms. Christie Paulson for her excellent assistance with this manuscript. We appreciate the assistance of the Center for Metabolic Bone Disease at the University of Alabama at Bimingham (P30 AR046031). We are also grateful for the assistance of the Small Animal Phenotyping Core, Metabolism Core, and Neuroscience Molecular Detection Core Laboratory at the University of Alabama at Bimingham (P30 NS0474666) and (P30AR048311). This work was supported by NIH grants RC 1DE-020533 (Y.P.L) and AR-055307 (Y.P.L.). The authors declare no competing financial interests.

\section{References}

1 Chambrone L, Guglielmetti MR, Pannuti CM, Chambrone LA. Evidence grade associating periodontitis to preterm birth and/or low birth weight: I. A systematic review of prospective cohort studies. J Clin Periodontol. 2011;38:795-808.

2 Kuula H, Salo T, Pirilä E, Tuomainen AM, Jauhiainen M, Uitto VJ, Tjäderhane L, Pussinen PJ, Sorsa T. Local and systemic responses in matrix metalloproteinase 8-deficient mice during Porphyromonas gingivalis-induced periodontitis. Infect Immun. 2009;77: 850-859.

3 Van Dyke TE, Serhan CN. Resolution of inflammation: a new paradigm for the pathogenesis of periodontal diseases. J Dent Res. 2003;82:82-90.

4 D'Aiuto F, Parkar M, Andreou G, Suvan J, Brett PM, Ready D, Tonetti MS. Periodontitis and systemic inflammation: control of the local infection is associated with a reduction in serum inflammatory markers. J Dent Res. 2004;83:156-160.

5 Loe H. Periodontal disease. The sixth complication of diabetes mellitus. Diabetes Care. 1993;16:329-334.

6 Beck J, Garcia R, Heiss G, Vokonas PS, Offenbacher S. Periodontal disease and cardiovascular disease. J Periodontol. 1996;67:11231137.

www.boneresearch.org | Bone Research 
7 Linden GJ, Lyons A, Scannapieco FA. Periodontal systemic associations: review of the evidence. J Periodontol. 2013;84:S8-S19.

8 Silva MJ, Kajiya M, AlShwaimi E, Sasaki H, Hong J, Ok P, Rezende TM, Pagonis TC, White RR, Paster BJ, Stashenko P, Kawai T. Bacteria-reactive immune response may induce RANKLexpressing $\mathrm{T}$ cells in the mouse periapical bone loss lesion. J Endod. 2012;38:346-350.

9 Yang S, Chen W, Stashenko P, Li YP. Specificity of RGS10A as a key component in the RANKL signaling mechanism for osteoclast differentiation. J Cell Sci. 2007;120:3362-3371.

10 Schwartz Z, Goultschin J, Dean DD, Boyan BD. Mechanisms of alveolar bone destruction in periodontitis. Periodontol 2000. 1997;14:158-172.

11 Schwäble J, Choudhary C, Thiede C, Tickenbrock L, Sargin B, Steur C, Rehage M, Rudat A, Brandts C, Berdel WE, MüllerTidow C, Serve H. RGS2 is an important target gene of Flt3-ITD mutations in AML and functions in myeloid differentiation and leukemic transformation. Blood. 2005;105:2107-2114.

12 Hurst JH, Hooks SB. Regulator of G-protein signaling (RGS) proteins in cancer biology. Biochem Pharmacol. 2009;78:12891297.

13 Yang S, Li YP. RGS10-null mutation impairs osteoclast differentiation resulting from the loss of $[\mathrm{Ca} 2+]$ i oscillation regulation. Genes Dev. 2007;21:1803-1816.

14 García-Bernal D, Dios-Esponera A, Sotillo-Mallo E, GarcíaVerdugo R, Arellano-Sánchez N, Teixidó J. RGS10 restricts upregulation by chemokines of $\mathrm{T}$ cell adhesion mediated by a $4 \beta 1$ and $\alpha L \beta 2$ integrins. J Immunol. 2011;187:1264-1272.

15 Shankar SP, Wilson MS, DiVietro JA, Mentink-Kane MM, Xie Z, Wynn TA, Druey KM. RGS16 attenuates pulmonary Th2/Th17 inflammatory responses. J Immunol. 2012;188:6347-6356.

16 Blair HC, Robinson LJ, Zaidi M. Osteoclast signalling pathways. Biochem Biophys Res Commun. 2005;328:728-738.

17 Conus S, Simon HU. Cathepsins and their involvement in immune responses. Swiss Med Wkly. 2010;140:w13042.

18 Asagiri M, Hirai T, Kunigami T, Kamano S, Gober HJ, Okamoto K Nishikawa K, Latz E, Golenbock DT, Aoki K, Ohya K, Imai Y, Morishita Y, Miyazono K, Kato S, Saftig P, Takayanagi H. Cathepsin K-dependent toll-like receptor 9 signaling revealed in experimental arthritis. Science. 2008;319:624-627.

19 Sasaki H, Suzuki N, Kent R Jr, Kawashima N, Takeda J, Stashenko P. T cell response mediated by myeloid cell-derived IL-12 is responsible for Porphyromonas gingivalis-induced periodontitis in IL-10-deficient mice. J Immunol. 2008;180:6193-6198.

20 Feng S, Deng L, Chen W, Shao J, Xu G, Li YP. Atp6v1c1 is an essential component of the osteoclast proton pump and in F-actin ring formation in osteoclasts. Biochem J. 2009;417:195-203.

21 Kelly KA, Tanaka S, Baron R, Gimble JM. Murine bone marrow stromally derived BMS2 adipocytes support differentiation and function of osteoclast-like cells in vitro. Endocrinology. 1998;139: 2092-2101.

Alexander B, Warner-Schmidt J, Eriksson T, Tamminga C,
Arango-Lievano M, Ghose S, Vernov M, Stavarache M, Musatov S, Flajolet M, Svenningsson P, Greengard P, Kaplitt MG. Reversal of depressed behaviors in mice by p11 gene therapy in the nucleus accumbens. Sci Transl Med. 2010;2:54ra76.

23 Tomar RS, Matta H, Chaudhary PM. Use of adeno-associated viral vector for delivery of small interfering RNA. Oncogene. 2003;22:5712-5715.

24 Hommel JD, Sears RM, Georgescu D, Simmons DL, DiLeone RJ. Local gene knockdown in the brain using viral-mediated RNA interference. Nat Med. 2003;9:1539-1544.

25 Sasaki H, Okamatsu Y, Kawai T, Kent R, Taubman M, Stashenko P. The interleukin-10 knockout mouse is highly susceptible to Porphyromonas gingivalis-induced alveolar bone loss. J Periodontal Res. 2004;39:432-441.

26 Carter BJ. Adeno-associated virus vectors in clinical trials. Hum Gene Ther. 2005;16:541-550.

27 Trepagnier CM, Madden RM, Lazzari EP. Quantitative study of sodium hypochlorite as an in vitro endodontic irrigant. J Endod. 1977;3:194-196.

28 Jiang H, Chen W, Zhu G, Zhang L, Tucker B, Hao L, Feng S, Ci H, Ma J, Wang L, Stashenko P, Li YP. RNAi-Mediated Silencing of Atp6i and Atp6i Haploinsufficiency Prevents Both Bone Loss and Inflammation in a Mouse Model of Periodontal Disease. PLoS One. 2013;8:e58599.

29 Ma J, Chen W, Zhang L, Tucker B, Zhu G, Sasaki H, Hao L, Wang L, Ci H, Jiang H, Stashenko P, Li YP. RNA interference-mediated silencing of Atp6i prevents both periapical bone erosion and inflammation in the mouse model of endodontic disease. Infect Immun. 2013;81:1021-1030.

30 Chen W, Yang S, Abe Y, Li M, Wang Y, Shao J, Li E, Li YP. Novel pycnodysostosis mouse model uncovers cathepsin $\mathrm{K}$ function as a potential regulator of osteoclast apoptosis and senescence. Hum Mol Genet. 2007;16:410-423.

31 Beadling C, Druey KM, Richter G, Kehrl JH, Smith KA. Regulators of $G$ protein signaling exhibit distinct patterns of gene expression and target $G$ protein specificity in human lymphocytes. J Immunol. 1999;162:2677-2682.

32 Cho H, Kozasa T, Takekoshi K, De Gunzburg J, Kehrl JH. RGS14, a GTPase-activating protein for Gialpha, attenuates Gialpha- and G13alpha-mediated signaling pathways. Mol Pharmacol. 2000;58: 569-576

33 Scheschonka A, Dessauer CW, Sinnarajah S, Chidiac P, Shi CS, Kehrl JH. RGS3 is a GTPase-activating protein for g(ialpha) and $\mathrm{g}$ (qalpha) and a potent inhibitor of signaling by GTPase-deficient forms of g(qalpha) and g(11alpha). Mol Pharmacol. 2000;58: 719-728.

34 Heximer SP, Cristillo AD, Forsdyke DR. Comparison of mRNA expression of two regulators of G-protein signaling, RGS1/BL34/ 1R20 and RGS2/G0S8, in cultured human blood mononuclear cells. DNA Cell Biol. 1997;16:589-598.

35 Baker PJ, Evans RT, Roopenian DC. Oral infection with Porphyromonas gingivalis and induced alveolar bone loss in immuno- 
competent and severe combined immunodeficient mice. Arch Oral Biol. 1994;39:1035-1040.

Wilensky A, Polak D, Awawdi S, Halabi A, Shapira L, HouriHaddad Y. Strain-dependent activation of the mouse immune response is correlated with Porphyromonas gingivalis-induced experimental periodontitis. J Clin Periodontol. 2009;36:915-921.

37 Trindade SC, Olczak T, Gomes-Filho IS, de Moura-Costa LF, Vale VC, Galdino-Neto M, Alves Dos Santos H, de Carvalho Filho PC, Stocker A, Bendicho MT, Xavier MT, de Moraes Marcílio Cerqueira E, Meyer R. Porphyromonas gingivalis HmuY-induced production of interleukin- 6 and IL-6 polymorphism in chronic periodontitis. J Periodontol. 2013;84:650-655.

38 Krajewski AC, Biessei J, Kunze M, Maersch S, Perabo L, Noack MJ. Influence of lipopolysaccharide and interleukin-6 on RANKL and OPG expression and release in human periodontal ligament cells. APMIS. 2009;117:746-754.

39 Musatov S, Chen W, Pfaff DW, Kaplitt MG, Ogawa S. RNAimediated silencing of estrogen receptor $\{$ alpha $\}$ in the ventromedial nucleus of hypothalamus abolishes female sexual behaviors. Proc Natl Acad Sci U S A. 2006;103:10456-10460.

40 Yu H, Li Q, Herbert B, Zinna R, Martin K, Junior CR, Kirkwood KL. Anti-inflammatory effect of MAPK phosphatase-1 local gene transfer in inflammatory bone loss. Gene Ther. 2011;18:344-353.

41 Kunze M, Huber A, Krajewski A, Lowden E, Schuhmann N, Buening H, Hallek M, Noack M, Perabo L. Efficient gene transfer to periodontal ligament cells and human gingival fibroblasts by adeno-associated virus vectors. J Dent. 2009;37:502-508.

42 Cirelli JA, Park CH, MacKool K, Taba M Jr, Lustig KH, Burstein H, Giannobile WV. AAV2/1-TNFR:Fc gene delivery prevents periodontal disease progression. Gene Ther. 2009;16:426-436.

43 Evans C. Arthritis gene therapy trials reach phase II. J Rheumatol. 2010;37:683-5.

44 Trombone AP, Claudino M, Colavite P, de Assis GF, AvilaCampos MJ, Silva JS, Campanelli AP, Ibanez OM, De Franco M, Garlet GP. Periodontitis and arthritis interaction in mice involves a shared hyper-inflammatory genotype and functional immunological interferences. Genes Immun. 2010;11:479-489.

45 Lundberg K, Wegner N, Yucel-Lindberg T, Venables PJ. Periodontitis in RA[mdash]the citrullinated enolase connection. Nat Rev Rheumatol. 2010;6:727-730.

46 de Pablo P, Chapple IL, Buckley CD, Dietrich T. Periodontitis in systemic rheumatic diseases. Nat Rev Rheumatol. 2009;5:218-224.

47 Demmer RT, Desvarieux M. Periodontal infections and cardiovascular disease: the heart of the matter. J Am Dent Assoc. 2006; 137:14S-20S.

48 Taubman MA, Valverde P, Han X, Kawai T. Immune response: the key to bone resorption in periodontal disease. J Periodontol. 2005;76:2033-2041.

49 Shay K. Infectious complications of dental and periodontal diseases in the elderly population. Clin Infect Dis. 2002;34:12151223 